\title{
Celebrating a Quarter-Century of Public Domain Research: 25th Annual Conference of the Health Care Systems Research Network
}

Sarah M. Greene Carolyn A. Taylor Suma Vupputuri

Follow this and additional works at: https://aah.org/jpcrr

Part of the Epidemiology Commons, Health Information Technology Commons, and the Health Services Research Commons

\section{Recommended Citation}

Greene SM, Taylor CA, Vupputuri S. Celebrating a quarter-century of public domain research: 25th annual conference of the Health Care Systems Research Network. J Patient Cent Res Rev. 2019;6:218-23. doi: $10.17294 / 2330-0698.1712$

Published quarterly by Midwest-based health system Advocate Aurora Health and indexed in PubMed Central, the Journal of Patient-Centered Research and Reviews (JPCRR) is an open access, peer-reviewed medical journal focused on disseminating scholarly works devoted to improving patient-centered care practices, health outcomes, and the patient experience. 


\title{
Celebrating a Quarter-Century of Public Domain Research: 25th Annual Conference of the Health Care Systems Research Network
}

\author{
Sarah M. Greene, MPH, ${ }^{1}$ Carolyn A. Taylor, PhD, MBA, ${ }^{2,3}$ Suma Vupputuri, $\mathrm{PhD}^{4}$ \\ ${ }^{1}$ Health Care Systems Research Network; ${ }^{2}$ George Mason University, Fairfax, VA; ${ }^{3}$ Taylor-Oden Enterprises, Inc., \\ Alexandria, VA; ${ }^{4}$ Mid-Atlantic Permanente Research Institute, Kaiser Permanente Mid-Atlantic States, Rockville, MD
}

\begin{abstract}
The 25th annual conference of the Health Care Systems Research Network (HCSRN) was held April 10-12 in Portland, Oregon, attracting 420 attendees. The HCSRN, a consortium of 18 communitybased research organizations embedded in or affiliated with large health care delivery systems, has hosted annual research conferences since 1994. The primary objective of the conference is to convene researchers, project staff, funders, and other stakeholders to share latest scientific findings and cultivate new partnerships among research teams, patients, and clinicians. Collaboration is the cornerstone of the HCSRN's success; the conference serves as a catalyst for a variety of collaborative ventures as well as tactics and approaches to more effective and efficient research. This year's program included 70 distinct scientific presentations, plus nearly 100 posters, and spanned diverse content offerings that mirrored the diversity of the HCSRN and its collaborators. Plenary sessions imparted insights on ways that data science and approaches to collaborative design in health care can speed the translation of research into practice. (J Patient Cent Res Rev. 2019;6:218-223.)
\end{abstract}

Keywords research network; learning health system; applied research; collaboration; data science

$\mathrm{T}$ he Health Care Systems Research Network (HCSRN, formerly the HMO Research Network) is a consortium of 18 communitybased research organizations (17 in the United States and 1 in Israel) embedded in or affiliated with large health care delivery systems (Figure 1). It is a longstanding "intellectual home" for delivery system-based scientists, offering a unique environment in which to conduct and disseminate practical research to solve real-world health and health care challenges.

Each year since 1994, the HCSRN has held an annual conference to convene, connect, and catalyze research that is responsive to national, regional, and local health

Correspondence: Sarah M. Greene, MPH,

Executive Director, Health Care Systems Research Network (sarahgreene@hcsrn.org) care priorities. The theme of the 2019 conference was "Celebrating Health Research," in recognition of the HCSRN's 25th anniversary of its founding. As part of the program, the conference honored several research scientists who were central in building this network 25 years ago: Mitch Greenlick, former director, Center for Health Research at Kaiser Permanente Northwest (Portland, OR); Mark Hornbrook, retired senior research investigator, Center for Health Research at Kaiser Permanente Northwest; and Joe Selby, former director, Division of Research at Kaiser Permanente Northern California (Oakland, CA).

Traditionally the HCSRN conference had been "hosted" by one of the member sites, and conference planning and organization were led by the hosting site under the direction of the network's executive director. However, for the first time in 2019, the conference used a multisite planning committee, which included individuals with diverse roles and experience, to plan 


\section{HEALTH CARE SYSTEMS RESEARCH NETWORK}

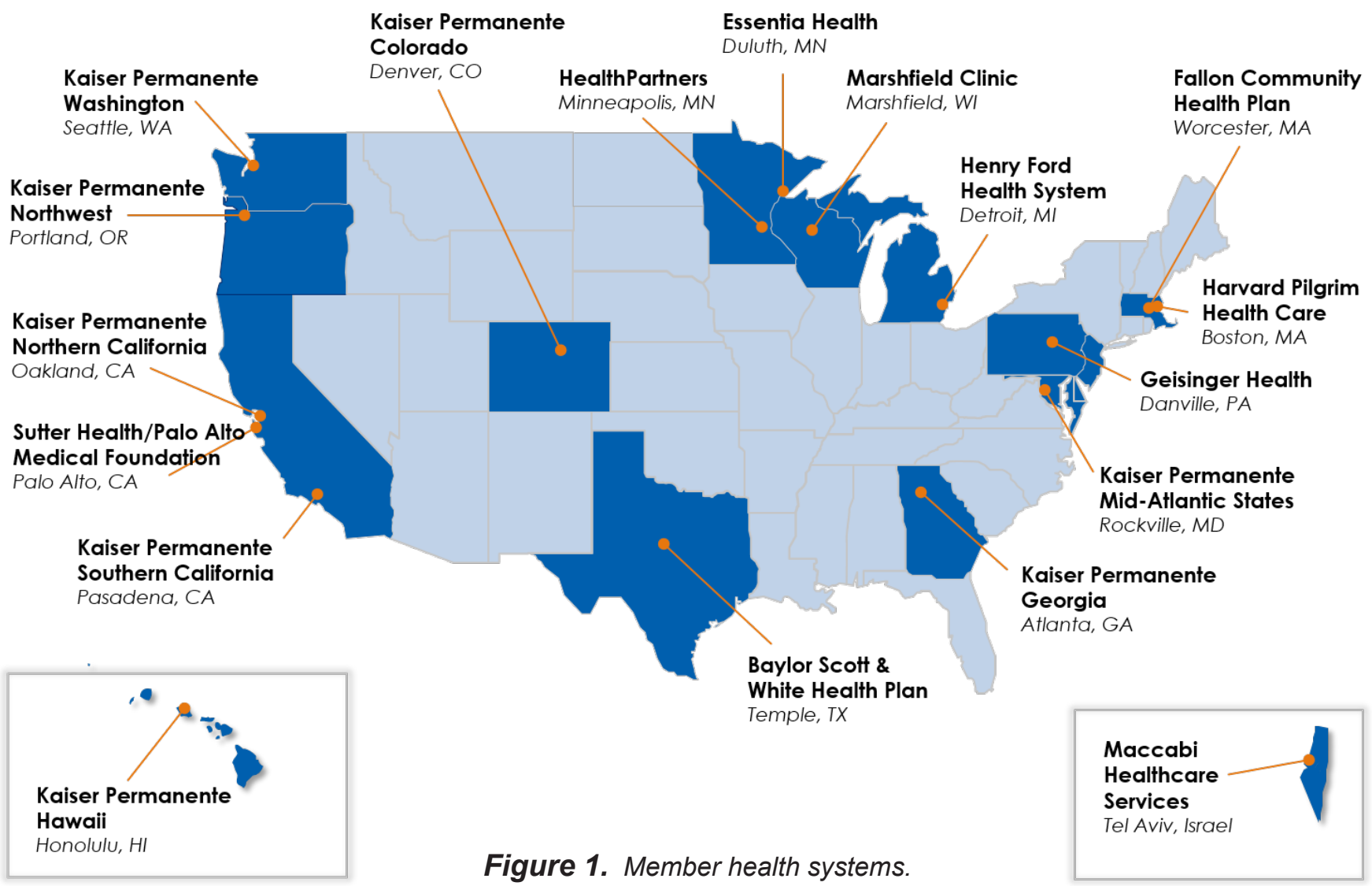

the program's content and structure. This change accomplished two objectives: reducing the burden on member sites, since hosting entails significant time and local resources; and, importantly, promoting new ideas, broader engagement, and enriched enthusiasm. Researchers and other partners (including a patient, a communication director, and a project manager) from 7 HCSRN sites collaborated on program development, which was organized around 3 tracks: research and results; practical application; and data science and informatics.

The program was comprised of 3 plenary sessions, 8 panels, 15 concurrent sessions in which 59 oral abstracts were presented, and 94 poster presentations. Topics addressed in these sessions reflected the range of subject matter expertise across the HCSRN and other organizations, including mental health; approaches to evidence dissemination in the front lines of health care delivery; cancer screening, prevention, and control; health equity; and impact of multiple chronic conditions in aging populations. Two especially noteworthy sessions at this year's conference were an exploration of gender diversity, equity, and inclusivity among HCSRN sites and a session that examined key tactics and effective practices for communicating research results to promote more widespread uptake in practice.

The HCSRN's ability to offer diverse but pragmatic content that appeals to a wide range of attendees, from research scientists and data analysts to policymakers and patients, is an asset for the broader research community, even as it obligates planning committee members to carefully consider the varied interests and backgrounds of its attendees. To this end, the opening and closing plenary sessions - focused on data science and artificial intelligence (AI), and collaboration between researchers and designers to improve health 
care, respectively - illustrated the disparate offerings that resonate across the network. We attribute this to the fact that many attendees, by virtue of being "embedded" researchers in their respective care delivery systems, have a unique appreciation for the multiplicity of challenges inherent in improving health and health care.

\section{Plenary Sessions}

Day 1: The first plenary session on the intersection between data science and health systems research offered a broad look at opportunities for data science to contribute to health advances in the populations HCSRN serves. It was organized as a moderated panel discussion featuring Joe Selby, executive director of the Patient-Centered Research Outcomes Institute (Washington, DC) and former board member of the HCSRN, as session moderator. Panelists Peter Embi, associate dean for informatics and health services research at Indiana University (Bloomington, IN), and Adam Wilcox, professor of biomedical informatics and medical education at University of Washington (Seattle, WA), represented academic health systems, while Nancy Morden, principal researcher at Microsoft Healthcare (Redmond, WA), offered a perspective from the private sector.

Together, the panelists and moderator explored the facets of data science that are suffusing health care, such as predictive analytics and machine learning, and engaged in a dialogue about the promise of $\mathrm{AI}$ in service to better health outcomes. They also offered sobering points-of-view about the hype surrounding AI, noting that it will not replace health care and caring outright, but it may have beneficial applications in certain parts of the care system, such as radiology and other fields reliant on medical imaging.

The issue of data quality at health systems also was discussed, and panelists noted the difficulty in assessing the relative quality of electronic health data at a high level. Panelists suggested that data should be "fit for purpose," with quality assessed according to specific needs. Panelists also weighed in on the issue of clinical prediction algorithms embedded within electronic medical record platforms and their importance in facilitating decision-making and complementing clinical work. Acknowledging that "automating" a course of action is not always appropriate when decisions are complex, panelists emphasized that algorithms can overcome human limitations and aid in clinical decision-making. Clinicians' skepticism of algorithms, while healthy, may impede the effective use of automated algorithms, and one panelist suggested that there was a need to train clinicians to critically discern when algorithms are useful adjuncts for decisions about care.

Day 2: The second plenary session consisted of the 2019 awards presentation and annual State of the Network address. Awards were given in 4 categories: early career investigator (distinguished by promising research); best paper utilizing the HCSRN's chief assets (eg, data, health systems, diverse patient population); ${ }^{1}$ outstanding posters (based on attendees' votes); and mentor of the year. Table 1 lists the 2019 awardees.

Table 1. Recipients of 2019 HCSRN Awards

\begin{tabular}{l|l}
\hline Award & Recipient Name (Organization) \\
\hline Mentor of the Year & $\begin{array}{l}\text { Douglas Corley, MD, PhD } \\
\text { (Division of Research, Kaiser } \\
\text { Permanente Northern California) }\end{array}$ \\
\hline $\begin{array}{l}\text { Outstanding Early } \\
\text { Career Investigator }\end{array}$ & $\begin{array}{l}\text { Michael Gionfriddo, PharmD, PhD } \\
\text { (Geisinger Research, Geisinger } \\
\text { Health System) }\end{array}$ \\
\hline Paper of the Year ${ }^{1}$ & $\begin{array}{l}\text { Beth Waitzfelder, PhD } \\
\text { (Center for Health Research, } \\
\text { Kaiser Permanente Hawaii) }\end{array}$ \\
\hline Best Posters & $\begin{array}{l}\text { Amanda Petrik, MPH } \\
\text { (Center for Health Research, } \\
\text { Kaiser Permanente Northwest) } \\
\text { Kevin Kheder, MD } \\
\text { (Division of Research, Kaiser } \\
\text { Permanente Northern California) }\end{array}$ \\
\hline
\end{tabular}

Following the awards, Sarah Greene, HCSRN executive director, gave the State of the Network, which afforded an opportunity to celebrate the network's noteworthy accomplishments since its inception, including the very fact that it has existed as a vital and relevant part of the research enterprise for 25 years and that many of its investigators have participated in critical research outputs in vaccine safety, cancer control, suicide prevention, treatment of substance use and abuse disorders, and the impact of multiple chronic conditions 
in aging populations. Noting the changing landscape of health and health care over the last quarter-century, Greene's address also acknowledged the need to remain competitive, namely, through continued investment in the network's data infrastructure and other resources that facilitate multisite collaboration. She noted in her remarks that researchers must be conversant in the language of the end-users of our research, particularly health system leaders, who are more inclined to focus on the value proposition and return on investment associated with an intervention or health system change. Hence, she observed that "researchers must be able to convey not only the statistical significance of their research results, but also the clinical, operational, and financial significance."

Day 3: The final session, "Radical Collaboration and Co-Design: Increasing the Gravitational Pull of Research," presented by Estee Neuwirth from the Kaiser Permanente Design Consultancy (Oakland, $\mathrm{CA}$ ), gave attendees a window into the ways that user-centered design is being deployed across the Kaiser Permanente care delivery system to address pervasive challenges, such as care for individuals with subclinical depression. She described how data and analytics by themselves are essential for transforming health care; however, adding human-centered design leads to a more impactful and compelling approach to improve health and health care. While Neuwirth works closely with designers and user-experience experts, she leverages her background as an academically trained sociologist and health services researcher to produce meaningful improvements in care transitions, preventable readmissions, and the implementation of digital therapeutics for enhancing emotional health and wellness. Neuwirth also shared timely case studies, tools, and insights applicable to research that could be leveraged in a learning health system.

\section{Poster and Oral Abstract Sessions}

Poster sessions presented an array of content, showcasing the range of interests and capabilities across the HCSRN and other aligned organizations. Box 1 shows the topic areas used to organize the poster and oral abstract sessions. The peer review process ensured that abstracts selected for presentation were both scientifically meritorious and well-aligned with the network's mission and conference objectives.
Oral abstract presentations were chosen based on the highest-rated submissions and included some large, influential studies.

\section{Box 1. Poster Categories for HCSRN 2019}

- Cancer

- Cardiovascular disease

- Care improvement

- Child and adolescent health

- Chronic conditions, multimorbidity, aging populations

- Data science, informatics \& data models

- Genetics, genomics, precision medicine

- Health equity and social needs

- Health services delivery, utilization, and coverage

- Implementation science

- Maternal and perinatal care

- Mental health, alcohol \& substance use/abuse

- Methods, designs, analytic tools

- Patient, clinician, and health system engagement

- Population, community, and worksite health

A total of 94 posters demonstrated the network's broad experience and expertise in areas critical to transforming health care. Award recipients for best poster presentation (one from each poster session) were:

- Amanda Petrik - "Validation of a Predicted-Risk Model to Improve Completion of Colorectal Cancer Screening in Community Health Centers;" and

- Kevin Kheder - "Statin Therapy and Risk of Incident Diabetes Mellitus in Adults With Cardiovascular Risk Factors."

Oral sessions similarly represented a range of topics showcasing nationally recognized research conducted within the HCSRN. This year, 59 oral abstract presentations were given, including results from seminal National Institutes of Health-funded clinical trials. For example, Karen Margolis of HealthPartners Institute (Minneapolis, MN) presented findings from her HyperLink study, a cluster randomized trial assessing the long-term effects of home blood pressure telemonitoring and pharmacist management on blood pressure control. She showed that HyperLink's telemonitoring intervention was associated with lower blood pressures and a 50\% reduction in incident cardiovascular events after 5 years. 
While around two-thirds of conference attendees were from HCSRN member sites, non-HCSRN-affiliated presenters were represented throughout these topical areas and the conference's other sessions. The full slate of abstracts was published as a supplement to the Journal of Patient-Centered Research and Reviews. ${ }^{2}$

\section{Panel Sessions}

Panel sessions were first implemented at the conference in 2017 in response to attendee feedback and for the purpose of generating lively discussions that engage both the panelists and audience. Panels consisted of diverse stakeholders, often including patient and clinical partners, and focused on applied issues in health care delivery and research translation. Three standout panel discussions are summarized henceforth.

"Risk-Based Cancer Screening: Is the Juice Worth the Squeeze?" explored the controversy of risk-based cancer screening that could, on one hand, optimize the balance of benefits and harms from screening but, on the other hand, increase the complexity of clinical prevention and pose implementation issues for health systems. Implementing personalized screening regimens could constrain already limited health resources, and the impact on underserved populations is a prevailing concern.

"Women in Research: Best Practices and Changes Needed to Promote Gender Equity" aimed to start a conversation about gender equity in the HSCRN, an issue that has received significant attention in the scientific fields. In the introduction to the panel discussion, data collected from $83 \%$ of the HCSRN member sites showed the network is doing well in terms of the representation of women among research faculty - virtually all member sites had at least $50 \%$ women faculty. However, similar to national data, representation of women at network sites decreased as job rank increased. The panelists (4 women, 2 men) discussed structural and cultural issues related to gender equity, identified opportunities and challenges for organizational change within member sites, and shared powerful personal perspectives and experiences.

"Transforming Research Findings Into Action: Building a Communications Strategy to Promote Change at the Local, Regional, and State Level" featured researchers alongside a program manager and communications expert, who presented a case example of an intervention to increase colorectal cancer screening that was successfully deployed in an underscreened Medicaid/ Medicare population and is now primed for spread to a broader population. Panelists discussed tactics to effectively disseminate research findings to maximize uptake in practice, and attendees at this panel received an incisive tutorial on messaging, understanding audience segments, selecting optimal communication channels, and overcoming barriers.

\section{Other Conference Highlights}

An emergent focus for the HCSRN is on training and career development for early and mid-career researchers. Given the network's maturity, longtenured investigators, and deep expertise in delivery system science, the HCSRN is well-positioned to impart lessons and essential competencies ${ }^{3}$ to junior research scientists. Additionally, several network sites are now home to fellowship programs to train a new generation of delivery system scientists. To this end, a panel at the 2018 conference on approaches to training and mentoring led to the creation of a crosssite interest group to facilitate ongoing exchange of questions, approaches, and insights. Several members of the interest group met this year and agreed that the 2020 conference should include a concentration of programming focused on training, mentoring, and career development, such as simulated grant review meetings, skill-building for effective collaboration, or maximizing the value of a mentoring relationship.

Along with serving as a venue to disseminate research results, a cornerstone of the HCSRN annual conference has always been the opportunity to convene ancillary scientific interest group meetings, where researchers come together to discuss a specific new project, review progress on an existing project, or share ideas about new directions for the network. This year, 21 groups convened formally, including multisite project teams focused on aging, mental health, cancer, pharmacovigilance, and opioid management. The multisite research networks in cancer and mental health are long-standing "anchor" projects in the network and have been the source of hundreds of publications from dozens of projects. The local research center in Portland at Kaiser Permanente Northwest capitalized 
on having the HCSRN conference in its hometown by holding a special workshop on qualitative research techniques, and we anticipate additional workshops will be held in conjunction with future conferences.

\section{HCSRN Conference}

Planning is underway for the next HCSRN annual conference, to be held April 8-10, 2020, in Philadelphia, Pennsylvania. Goals and new ideas for this conference include activities to enhance networking, mentoring workshops aimed at junior scientists, invited panels of contemporary controversies, and increased participation from external research colleagues. The conference is open to everyone in the research community, including those from non-HCSRN sites, clinicians, patient partners, federal and industry partners, and others interested in improving health care for all. For more information or to join the conference updates email list, visit hcsrnmeeting.org.

\section{HCSRN in Summary}

The Health Care Systems Research Network has grown in both size and stature over the last 25 years, with more than 2000 scientists and research staff who study diverse populations cared for by member health systems and are supported by electronic health records and a pioneering common data model. ${ }^{4,5}$ Individually and collectively, HCSRN members exemplify the aspirational goal of the learning health system model, ${ }^{6}$ wherein evidence informs practice and practice informs evidence. The annual conference is a venue to share, hone, and refine the knowledge base for more effective health care and improved population health.

\section{Acknowledgments}

The authors thank the 2019 HCSRN planning committee, the conference management team at Conference Solutions (Portland, OR), and the HCSRN governing board for their contributions and support. We gratefully acknowledge financial sponsorship from the Patient-Centered Outcomes Research Institute. Finally, we thank the many attendees who served as volunteers at the conference.

\section{Conflicts of Interest}

None.

\section{References}

1. Waitzfelder B, Stewart C, Coleman KJ, et al. Treatment initiation for new episodes of depression in primary care settings. J Gen Intern Med. 2018;33:1283-91. CrossRef

2. Abstracts from the 25th annual Health Care Systems Research Network Conference, April 8-10, 2019, Portland, Oregon. J Patient Cent Res Rev. 2019;6:52-126. CrossRef

3. Forrest CB, Chesley FD Jr, Tregear ML, Mistry KB. Development of the learning health system researcher core competencies. Health Serv Res. 2018;53:2615-32. CrossRef

4. Hornbrook MC, Hart G, Ellis JL, et al. Building a virtual cancer research organization. $J$ Natl Cancer Inst Monogr. 2005;(35):12-25. CrossRef

5. Ross TR, Ng D, Brown JS, et al. The HMO Research Network Virtual Data Warehouse: a public data model to support collaboration. EGEMS (Wash DC). 2014;2(1):1049. CrossRef

6. Greene SM, Reid RJ, Larson EB. Implementing the learning health system: from concept to action. Ann Intern Med. 2012;157:207-10. $\underline{\text { CrossRef }}$

(C) 2019 Aurora Health Care, Inc. 